\title{
Konflik jemaat dan identitas sosial shema dalam 1 Korintus 12
}

Brury Eko Saputra

Sekolah Tinggi Teologi Aletheia, Lawang, Jawa Timur

brury@sttaletheia.ac.id

https://orcid.org/0000 0003-4449-9213

Keywords:

apostle Paul; conflict resolution;

Corinthian church; shema; social identity theory; jemaat Korintus; rasul Paulus; resolusi konflik; teori identitas sosial

\section{Article History}

Submitted: April 23, 2021

Revised: October 01, 2021

Accepted: October 10, 2021

DOI: https://doi.org/

10.30995/kur.v7i2.272

Scan this QR,

Read Online

口)

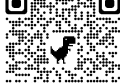

$6+13 t$
Abstract: This article aims to read the echo of the Shema in 1 Corinthians 12. Using the Social Identity Theory shows that the apostle Paul echoes the Shema when utilizing the oneness language in 1 Corinthians 12 . The theory also demonstrates that the Shema has social functions in 1 Corinthians 12 . The article concludes that reading the echo of the Shema 1 Corinthians in light of the Social Identity Theory contributes to understanding conflict resolution in the Corinthian church.

Abstrak: Artikel ini bertujuan membaca gema terhadap Shema dalam 1 Korintus 12. Dengan menggunakan pendekatan Teori Identitas Sosial, kajian ini menghasilkan bukti bahwa Rasul Paulus memang menggemakan Shema ketika menggunakan bahasa keesaan dalam 1 Korintus 12. Melalui Teori Identitas Sosial, ditunjukkan bahwa rujukan terhadap Shema tersebut memiliki fungsi sosial di 1 Korintus 12. Kesimpulannya, pembacaan terhadap gema Shema dalam 1 Korintus 12 dengan Teori Identitas Sosial memberikan kontribusi bagi pemahaman terhadap penyelesaian konflik yang dihadapi jemaat di Korintus.

Copyright: @2021, Authors.

\section{Pendahuluan}

1 Korintus 12 merupakan teks yang terkenal dalam sejarah kekristenan. Ada banyak tafsiran dan cara baca yang telah ditawarkan atas teks tersebut. Tafsiran terkini fokus pada isu penerimaan (inclusion) terhadap kelompok termarjinalisasi dalam jemaat. Pada tahun 2008, dalam artikelnya yang berjudul "One Body, Many Parts: A Reading of 1 Corinthians 12:12-27," Carol Troupe berupaya membaca teks 1 Korintus dengan Black and Womanist Theology. ${ }^{1}$ Menurutnya, jika dibaca sekilas pada level permukaan, teks 1 Korintus 12 memang seolah menyuarakan dan mendorong kesatuan serta interdependesi setiap anggota jemaat. Namun apabila dibaca secara lebih mendalam, teks tersebut justru mendorong adanya penolakan (exclusion) terhadap kelompok termarjinal karena sangat menekankan elemen hirarkis dalam jemaat. Dengan kata lain, kelompok termarjinal diharuskan menyesuaikan diri dengan kelompok yang lebih dominan (dalam analogi bagian tubuh merujuk pada mata atau bahkan kepala jika dibandingkan dengan

${ }^{1}$ Carol Troupe, "One Body, Many Parts: A Reading of 1 Corinthians 12:12-27," Black Theology 6, no. 1 (September 2008): 32-45. 
kaki). Oleh karena itu, dalam kesimpulannya ia berkata, "The Corinthians text is, for me, problematic and full of contradiction." ${ }^{2}$

Masih berbicara soal penerimaan (inclusion) dalam 1 Korintus 12, Brian Brock mencoba membaca teks tersebut dengan kerangka teori disabilitas dalam artikelnya yang berjudul "Theologizing Inclusion: 1 Corinthians 12 and the Politics of the Body of Christ." ${ }^{13}$ Menurutnya, gambaran tubuh dalam 1 Korintus 12 mendorong gereja untuk menerima karunia setiap anggotanya terlepas dari perbedaan secara sosiologis maupun demografis. ${ }^{4}$ Dalam kesimpulannya, ia mengatakan bahwa penerimaan terhadap setiap karunia (termasuk dari kelompok termarjinalisasi) harus dimulai dari mengesampingkan penanda status (status markers) sosial yang memisahkan setiap anggota. ${ }^{5}$

Pembacaan yang ditawarkan oleh Troupe dan Brock memberikan sumbangsih dalam mengidentifikasi adanya motif penerimaan (inclusion) ketika Paulus menulis 1 Korintus 12. Pembacaan dengan motif penerimaan sangat krusial mengingat 1 Korintus 12 ditulis dalam situasi konflik yang dialami oleh jemaat di Korintus. Namun, kedua pembacaan tersebut belum menyentuh aspek lain yang juga penting dalam 1 Korintus 12, yaitu persoalan identitas sosial jemaat. Oleh karena itu, dengan perhatian yang sama terhadap penerimaan (inclusion) kelompok yang termarjinalisasi, penulis akan membahas persoalan identitas yang muncul dalam teks tersebut dengan Teori Identias Sosial. Dengan membaca teks 1 Korintus 12 menggunakan Teori Identitas Sosial (Social Identity Theory), pembaca dapat menemukan strategi penerimaan yang diupayakan oleh Paulus dalam teks tersebut. Pembacaan menggunakan Teori Identitas Sosial di artikel ini akan fokus pada gema Shema dalam 1 Korintus 12 dan relasinya dengan persoalan yang dihadapi jemaat di sana. Pemilihan Teori Identitas Sosial sebagai sebagai pisau bedah dalam tulisan ini dikarenakan kecocokan pendekatan ini untuk menjelaskan pergumulan identitas sosial jemaat di Korintus di tengah konflik yang mereka hadapi. Penulis bukanlah orang pertama yang menerapkan teori tersebut ke dalam studi 1 Korintus (namun yang pertama terhadap gema Shema di Korintus), sehingga akan merujuk beberapa pakar yang telah menerapkannya di bagian pembahasan nantinya.

Penerapan analisis Teori Identitas Sosial terhadap gema Shema dikarenakan gema tersebut dimunculkan oleh Paulus sebagai strategi menjawab konflik di tengah jemaat sebagaimana diungkapkan oleh beberapa pakar yang akan penulis rujuk juga di bagian pembahasan. Artikel ini pertama-tama akan menunjukkan bahwa Rasul Paulus memang menggemakan Shema dalam 1 Korintus 12. Kemudian, rujukan terhadap Shema tersebut memiliki fungsi sosial yang dapat dibaca menggunakan Teori Identitas Sosial yang telah banyak digunakan dalam studi Perjanjian Baru. Di bagian akhir, penulis menyarankan bahwa pembacaan terhadap 1 Korintus 12 dengan Teori Identitas Sosial memberikan sumbangsih bagi pemahaman terhadap penyelesaian konflik yang dihadapi jemaat di Korintus.

\section{METODE}

Metode kerja artikel ini adalah kualitatif dengan memanfaatkan paradigma teoritis dalam bidang Psikologi dan Sosial Kognitif, yaitu pendekatan Teori Identitas Sosial. Pendekatan ini lahir dalam dunia psikologi sosial dan pertama kali digagas oleh Henri Tajfel yang kemudian dikembangkan oleh muridnya yang bernama John C. Turner. ${ }^{6}$ Dalam artikelnya, "Social Identity Theory

\footnotetext{
2 Ibid., 43-4.

${ }^{3}$ Brian Brock, "Theologizing Inclusion: 1 Corinthians 12 and the Politics of the Body of Christ," Journal of Religion, Disability and Health 15, no. 4 (October 2011): 351-376. Senada dengan Brock, Amos Yong mengungkapkan bahwa 1 Kor. 12 merupakan sebuah teks yang sangat kuat berbicara tentang penerimaan, termasuk terhadap orang difabel. Lih. Amos Yong, The Bible, Disability, and the Church: A New Vision of the People of God (Grand Rapids: Eerdmans, 2011).

${ }^{4}$ Brock, "Theologizing Inclusion: 1 Corinthians 12 and the Politics of the Body of Christ.", 352.

5 Ibid., 372.

${ }^{6}$ Untuk sejarah singkat dan elemen-elemen penting dalam teori tersebut, lihat: Philip F. Esler, "An Outline of Social Identity Theory," in T\&T Clark Handbook to Social Identity in the New Testament, ed. J. Brian Tucker and Coleman A. Baker (London: Bloomsbury, 2016).
} 
and Biblical Interpretation," Coleman A. Baker menjelaskan bahwa teori ini telah lama dan banyak digunakan dalam tafsir biblis oleh para pakar biblika. ${ }^{7}$ Saat ini, perkembangan penggunaan teori ini dalam studi Perjanjian Baru telah sampai pada diterbitkannya sebuah handbook ${ }^{8}$ dan tafsiran $^{9}$ berisi penerapan teori ini dalam teks Perjanjian Baru. Kedua karya tersebut mendorong sebuah proyek seri tafsiran yang masih berjalan dengan nama T\&T Clark Social Identity Commentaries on the New Testament.

Pembacaan dengan Teori Identitas Sosial berfokus pada gema Shema dalam 1 Korintus $12 .{ }^{10}$ Beberapa pertanyaan mengarahkan penerapan metode ini adalah tentang: Apa fungsi sosial dari gema Shema dalam 1 Korintus 12; Bagaimana Paulus menggunakan gema Shema dalam 1 Korintus 12 untuk menjelaskan identitas sosial jemaat di Korintus; Mengapa gema Shema dalam 1 Korintus 12 penting bari argumen Paulus secara keseluruhan.

\section{Hasil dan Pembahasan}

Menurut Timothy L. Carter, metafor tubuh yang digunakan dalam 1 Korintus 12 memang sebuah metafora yang terkenal di dunia kuno; pertanyaannya, bagaimana para pembaca surat Paulus memahami penggunaan metafor tersebut? Pesan apa yang akan ditangkap oleh penerima surat Paulus? ${ }^{11}$ Dalam bagian ini, dipaparkan pendapat para ahli terkait pemaknaan metafora tersebut dan mengusulkan bahwa metafora tersebut tidak dapat dipisahkan dari pengakuan iman terpenting bangsa Yahudi, yaitu Shema.

\section{Gema Shema dalam 1 Korintus 12}

Carter berpendapat bahwa rujukan terhadap kata-kata "yang lemah, tidak elok dan elok" (1 Kor. 12:22-24) dalam metafora tubuh di 1 Korintus 12 dapat dibaca dalam terang fisiologi Hippocrates dan Galen. ${ }^{12}$ Menurutnya, dalam konteks jemaat di Korintus, rujukan terhadap kata-kata tersebut dapat dihubungkan dengan ungkapan "yang kuat dan lemah" dalam 1 Korintus $8 .{ }^{13}$ Singkatnya, metafora tubuh dalam 1 Korintus 12 adalah strategi Paulus untuk membicarakan kembali persoalan perpecahan yang akut di tengah jemaat di Korintus.

Debra A. Reagan mengungkapkan bahwa metafor tubuh yang digunakan dalam 1 Korintus 12 bukanlah sebuah metafora semata, tetapi sebuah seruan untuk menghidupi ketubuhan secara nyata dalam komunitas sebagai seorang Kristen. ${ }^{14}$ Kecenderungan menolak iman yang hadir dalam ketubuhan akan berdampak pada penolakan terhadap anggota tubuh Kristus yang lainnya. ${ }^{15}$ Beberapa contoh penolakan yang diberikan oleh Reagan meliputi penolakan terhadap tubuh yang tersakiti dan terhadap seksualitas tubuh anggota tubuh Kristus. ${ }^{16}$ Pandangan Carter

\footnotetext{
${ }^{7}$ Coleman A. Baker, "Social Identity Theory and Biblical Interpretation," Biblical Theology Bulletin: Journal of Bible and Culture 42, no. 3 (August 2012): 129-138.

${ }^{8}$ J. Brian Tucker and Coleman A. Baker, eds., T\&T Clark Handbook to Social Identity in the New Testament (London: Bloomsbury, 2016).

${ }^{9} \mathrm{~J}$. Brian Tucker and Aaron Kuecker, eds., T\&T Clark Social Identity Commentary on the New Testament (London: Bloomsbury, 2020).

${ }^{10}$ Ada beberapa pakar telah menerapkan Teori Identitas Sosial untuk membaca teks 1 Korintus, hanya saja mereka tidak memberikan perhatian kepada kemunculan Shema dalam kitab tersebut. Beberapa karya pakar yang dimaksud mencakup: J. Brian Tucker, You Belong to Christ: Paul and the Formation of Social Identity in 1 Corinthians 1-4 (Eugene: Pickwick, 2010); J. Brian Tucker, "Remain in Your Calling": Paul and the Continuation of Social Identities in 1 Corinthians (Eugene: Pickwick, 2011); J. Brian Tucker, 1 Corinthians: A Social Identity Commentary (London: Bloomsbury, 2021); Kar Yong Lim, Metaphors and Social Identity Formation in Paul's Letters to the Corinthians (Eugene: Pickwick, 2017).

${ }^{11}$ Timothy L. Carter, "Looking at the Metaphor of Christ's Body in 1 Corinthians 12," in Paul: Jew, Greek and Roman, ed. Stanley E. Porter (Leiden: Brill, 2008), 94-9.

12 Ibid., 100-5.

13 Ibid., 106.

14 Debra A. Reagan, "Reclaiming the Body for Faith," Interpretation: A Journal of Bible and Theology 67, no. 1 (January 3, 2013): 44-51, accessed April 16, 2021, http://journals.sagepub.com/doi/10.1177/0020964312463331.

15 Ibid., 51.

16 Ibid., 51-5.
} 
dan Reagan memberikan perhatian khusus pada relasi antara metafora tubuh dalam 1 Korintus 12 dan persoalan yang terjadi di jemaat Korintus (e.g., masalah dalam 1 Korintus 8 dan persoalan peno-lakan terhadap anggota jemaat yang dipandang berbeda). Memang, pembacaan terhadap 1 Korintus 12 tidak dapat dilepaskan dari dimensi sosial dan politis yang dihidupi oleh jemaat saat itu. Kendatipun demikian, pembacaan yang mereka tawarkan kurang memberikan perhatian pada kemunculan kata "satu" yang sangat dominan dalam 1 Korintus 12. Kekosongan tersebut diisi oleh temuan Andrew Byers dalam artikelnya yang berjudul The One Body of the Shema in 1 Corinthians: An Ecclesiology of Christological Monotheism. Menurut Byers, pengaruh retorika Greco-Roman (homonoia) terhadap metafora di 1 Korintus 12 bersifat sekunder. Pengaruh primer diperoleh dari gema terhadap Shema yang sudah muncul dalam 1 Korintus 8:6 dan kemudian ditekankan kembali dalam 1 Korintus $12 .{ }^{17} \mathrm{Hal}$ itu menjelaskan mengapa penggunaan kata satu sangat dominan di 1 Korintus 12.

Pendapat Byers dapat diterima karena dua alasan yang sangat mendasar. Pertama, gema terhadap Shema dalam bentuk bahasa keesaan (oneness language) kerap kali muncul dalam teksteks yang bersifat polemis. Kemunculannya memberikan tekanan pada keesaan Allah dan umat Allah. Dalam teks-teks polemis tersebut, misalnya 1 Korintus 8, tekanan utama bahasa ke-esaan cenderung bersifat relational dan revelational. Relational artinya menekankan relasi antara Allah dan umat-Nya, revelational artinya menegaskan keesaan Allah yang harus terlihat dalam kesatuan umat. Kedua poin tersebut terlihat jelas dalam penggunaan kata satu di 1 Korintus $12 .{ }^{18}$ Kedua, sebagaimana dijelaskan oleh Byers persoalan perpecahan jemaat dan solusi yang Paulus bahas di 1 Korintus. 12 sudah muncul dalam 1 Korintus $8 .{ }^{19}$ Mulai dari 1 Korintus 8 hingga pasal 10, bahasa keesaan (dengan penggunaan kata satu) memiliki rujukan terhadap Shema. ${ }^{20}$ Dengan membandingkan pergerakan argumen Paulus serta ide yang hendak dikomunikasikan dari 1 Korintus 8 hingga pasal 12, pembaca dapat menemukan bahwa gema Shema memang ha-dir dalam teks-teks tersebut. ${ }^{21}$

Setelah menjelaskan bahwa penggunaan kata satu di 1 Korintus 12 memiliki relasi yang erat dengan Shema, Byers menemukan bahwa rujukan terhadap Shema dalam tulisan Josephus dan Philo tidak hanya bersifat teologis tetapi juga sosiologis. ${ }^{22}$ Menurut Byers, gema Shema dalam 1 Korintus 12 memiliki dua fungsi sosial, yaitu: "establishing and enforcing boundary demarcation lines that preserved the uniqueness of the people of the one and only Deity." ${ }^{23}$ Dengan kata lain, fungsi tersebut bersifat internal dengan menegaskan kembali kesatuan jemaat di dalam Allah yang satu-satunya dan bersifat eksternal dengan memberikan batasan sosial antara jemaat Korintus dan komunitas lain.

${ }^{17}$ Andrew Byers, "The One Body of the Shema in 1 Corinthians: An Ecclesiology of Christological Monotheism," New Testament Studies 62, no. 4 (October 1, 2016): 518, accessed April 16, 2021, https://www.cambridge.org/core/journals/new-testament-studies/article/abs/one-body-of-the-shema-in-1-corinthiansan-ecclesiology-of-christological-monotheism/270C5C456AFF852A178032573270D902.

${ }^{18}$ Brury Eko Saputra, The Shema and John 10: The Importance of the Shema Framework in Understanding the Oneness Language in John 10 (Eugene: Wipf and Stock, 2019), 9-10.

${ }^{19}$ Lihat beberapa tulisan berikut: N. T. Wright, The Climax of the Covenant: Christ and the Law in Pauline Theology (London: T\&T Clark, 1991), 120-36; Richard Bauckham, "Confessing the Cosmic Christ (1 Corinthians 8:6 and Colossians 1:15-20)," in Monotheism and Christology in Greco-Roman Antiquity, ed. Matthew V. Novenson

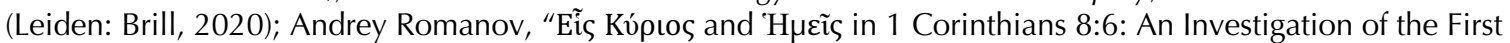
Person Plural in Light of the Lordship of Jesus Christ," Neotestamentica 49, no. 1 (2015): 47-74, accessed April 17, 2021, https://muse.jhu.edu/article/638884; .

${ }^{20}$ Erik Waaler, The Shema and The First Commandment in First Corinthians: An Intertextual Approach to Paul's Re-Reading of Deuteronomy (Tübingen: Mohr Siebeck, 2008), 49-100. 31.

${ }^{21}$ Byers, "The One Body of the Shema in 1 Corinthians: An Ecclesiology of Christological Monotheism." 524-

22 Ibid. 521-3.

23 Ibid., 520. 


\section{Pembacaan Teori Identitas Sosial terhadap Gema Shema dalam 1 Korintus 12}

Kar Yong Lim berpendapat bahwa penggunaan metafora dalam surat 1 Korintus memiliki fungsi sosial sebagai referensi terhadap formasi identitas jemaat di Korintus. ${ }^{24}$ Dengan menggunakan Teori Identitas Sosial, Lim mengatakan bahwa metafora tubuh dalam 1 Korintus 12 menekankan kesatuan serta kebersamaan dalam sebuah komunitas sebagai dasar nasihat etis Paulus kepada jemaat di Korintus. ${ }^{25}$ Sama seperti Lim, kajian ini menganalisis metafora tubuh dalam 1 Korintus dengan Teori Identitas Sosial. Namun, berbeda dari Lim, fokus penulis adalah pada gema Shema dalam metafor tersebut.

\section{Formasi Identitas Sosial Jemaat Korintus: Tiga Level Identitas Sosial}

Turner, seperti yang dikutip oleh Baker, sebagai orang yang meneruskan Teori Identitas Sosial Tajfel, mengembangkan teori tersebut pada analisis identitas kelompok secara internal (dikenal dengan istilah Self-Categorization Theory). ${ }^{26}$ Menurut teori tersebut, identitas sosial dapat dikelompokkan menjadi tiga tingkatan yakni superordinate identity, ingroup identity, dan subordinate identity. ${ }^{27}$ Superordinate identity merupakan sebuah kategori identitas yang dapat menyatukan atau mendifinisikan identitas sebuah kelompok (e.g., identitas sebuah denominasi secara sinodal). Ingroup identity merujuk pada identitas sub-group yang ada di dalam sebuah kelompok (e.g., gereja lokal dalam sebuah sinode dengan denominasi tertentu). Subordinate identity merujuk pada identitas personal yang dimiliki oleh setiap anggota kelompok (e.g., keunikan personal setiap anggota jemaat dalam gereja lokal).

Dinamika sosial yang digambarkan dalam 1 Korintus 12 sangat berhubungan dengan formasi identitas sosial jemaat. Penjelasan Paulus tentang fungsi pelayanan yang beragam namun disatukan oleh satu Roh, satu Tuhan dan satu Allah (1 Korintus 12:4-11) sama dengan penggunaan metafora fungsi tubuh yang beragam tetapi disatukan oleh satu kepala (1 Korintus 12:1220). Berdasarkan penjelasan Paulus, dasar kesatuan jemaat adalah keesaan Allah. Hal tersebut jelas menggemakan kembali fungsi Shema sebagaimana dipahami oleh Philo (Philo, Spec. 1.52; 4.159; Virt. 35) ${ }^{28}$ dan Josephus (Josephus, Ant. 5.111). ${ }^{29}$ Bagi bangsa Yahudi, kesatuan mereka merupakan dampak dari relasi covenantal mereka dengan Allah yang mereka sembah dalam pengakuan Shema (bdk. Kej 12; UI. 27-30; Jub. 12:19-20). Menurut Tucker, fondasi yang sama - yaitu panggilan dan perjanjian dengan Allah - juga dapat ditemukan dalam identitas sosial jemaat di Korintus. ${ }^{30}$

Berdasarkan tiga tingkatan identitas dalam Teori Identitas Sosial, gema terhadap Shema memiliki fungsi sebagai superordinate identity. Artinya, keyakinan dan relasi dengan Allah yang satu dan sama harus menjadi penanda dari identitas sosial jemaat di Korintus. Fungsi Shema yang sama juga hadir dalam gemanya di 1 Korintus 8:6. Dalam 1 Korintus 8:6 Paulus menekankan bahwa identitas jemaat di Korintus bukan ditentukan oleh sub-group yang dominan, baik yang mengonsumsi ataupun tidak mengonsumsi makanan yang telah dipersembahan kepada ber-hala. Identitas mereka ditentukan oleh keyakinan dan relasi mereka terhadap Allah yang mereka imani

\footnotetext{
${ }^{24}$ Kar Yong Lim, Metaphors and Social Identity Formation in Paul's Letters to the Corinthians (Eugene: Pickwick, 2017), 196-201.

25 Ibid., 197.

${ }^{26}$ Baker, "Social Identity Theory and Biblical Interpretation." 130

${ }^{27}$ Penelitian Turner terkait hal ini dapat dilihat di John C. Turner, Rediscovering the Social Group: SelfCategorization Theory (New York: Blackwell, 1987), 19-26; bdk. Baker, "Social Identity Theory and Biblical Interpretation." 130.

${ }^{28}$ C. D. Yonge, The Works of Philo: Complete and Unabridged, New Updated Edition (Peabody: Hendrickson, 1993).

${ }^{29}$ Flavius Josephus, The Works of Josephus: Complete and Unabridged, New Updated Edition, ed. William Whiston (Peabody: Hendrickson, 1980).

30 Tucker, You Belong to Christ: Paul and the Formation of Social Identity in 1 Corinthians 1-4, 130-2.
} 
dalam Shema. ${ }^{31}$ Jika dikaitkan kembali dengan persoalan yang terjadi di 1 Korintus 12 , maka identitas sosial Shema berperan sebagai rujukan untuk menentukan keanggotan mereka dalam sebuah jemaat. Dengan demikian, kehadiran gema Shema memberikan penegasan bahwa identitas sosial jemaat tidak boleh didikte oleh dominasi sekelompok orang yang memiliki karunia tertentu semata, tetapi di dalam relasi dengan Allah yang satu.

Salah satu peran penting dari superordinate identity dalam Teori Identitas Sosial adalah menentukan batas komunitas (social boundary). ${ }^{32}$ Dengan hadirnya gema Shema sebagai superordinate identity dalam 1 Korintus 12, batas antara insider dan outsider ditegaskan kembali. Keanggotaan jemaat di Korintus tidak ditentukan oleh faktor kesukuan, gender maupun karunia yang dimiliki oleh jemaat, tetapi relasi dengan Allah yang mereka imani di dalam Shema. Tekanan terhadap fungsi gema Shema sebagai batas komunitas telah muncul sejak di 1 Korintus 3:8; Paulus menekankan bahwa "baik yang menanam maupun yang menyiram adalah sama." Yang dimaksudkan oleh Paulus sama dalam ayat tersebut adalah identitas yang sama sebagai rekan sekerja Allah (1Kor. 3:9). Identitas sosial yang sama tersebut tidak didefinisikan oleh talenta atau karya mereka (baik yang menaman ataupun menyiram), tetapi Allah sebagai yang memberikan pertumbuhan. ${ }^{33}$ Oleh karena itu, tekanan Paulus pada kata satu yang menggemakan Shema dalam 1 Korintus 12 dapat dibaca sebagai seruan kepada jemaat untuk memikirkan kembali identitas sosial mereka sebagai orang-orang yang telah dipanggilan untuk hidup dalam perjanjian dengan Allah (1Kor. 12:2-3).

Selain membicarakan tentang kesatuan, Paulus juga menjelaskan tentang pentingnya keberagaman di tengah jemaat. Sama seperti tubuh disusun oleh berbagai anggota dengan tugas berbeda-beda (1Kor. 12:12-20), demikian juga jemaat di Korintus (1Kor. 12:4-11). Menurut Teori Identitas Sosial, keberagaman tersebut dapat dipandang sebagai ingroup identity dan subordinate identity. Sebagai ingroup identity jemaat di Korintus mungkin saja punya kedekatan kultural yang khusus dengan yang sesuku ataupun dengan status sosial yang sama; 1 Korintus 12:13 dengan jelas menyebut adanya orang Yahudi dan Yunani, orang merdeka dan budak. Jika itu dilihat sebagai ingroup identity, maka kedekatan seorang anggota jemaat terhadap suku atau status sosial tertentu perlu dipandang sebagai sebuah kekayaan yang dimiliki jemaat, bukan sebuah ancaman bagi jemaat. Untuk dapat memandangnya sebagai sebuah kekayaan, maka perlu ada penerimaan terhadap ingroup yang lain dalam superordinate identity yang satu itu. Sama seperti ingroup identity, mungkin saja dalam setiap suku atau status sosial ada orang-orang tertentu memiliki karunia tertentu (seperti bernubuat, mengajar, atau yang lainnya; subordinate identity), maka itu harus dipandang sebagai kekayaan bagi ingroup dan superordinate identity.

\section{Sikap terhadap Komunitas: Tiga Aspek Identitas Sosial}

Dalam karyanya pada tahun 1978an, Tajfel telah mengidentifikasi adanya tiga aspek yang sangat penting dalam identitas sosial yaitu aspek kognitif, evaluatif, dan emosional. ${ }^{34}$ Aspek kognitif merujuk pada kemampuan mengidenfikasi keanggotannya dalam sebuah identitas sosial. Aspek evaluatif menekankan kemampuan untuk mendeteksi nilai-nilai yang melekat pada kelompoknya. Aspek emosional berhubungan dengan sikap seseorang terhadap kelompoknya dan yang bukan kelompoknya. ${ }^{35}$ Menurut Esler, ketiga aspek tersebut memberikan alat untuk mengukur bagaimana sikap seorang anggota komunitas terhadap kelompoknya dan kelompok luar. ${ }^{36}$

${ }^{31}$ Bdk. Wright, The Climax of the Covenant: Christ and the Law in Pauline Theology, 132-5.

${ }^{32}$ Baker, "Social Identity Theory and Biblical Interpretation." 130-1.

${ }^{33}$ Saputra, The Shema and John 10: The Importance of the Shema Framework in Understanding the Oneness Language in John 10, 59-60.

${ }^{34}$ Henri Tajfel, "Interindividual Behavior and Intergroup Behavior," in Differentiation between Social Groups: Studies in the Social Psychology of Intergroup Relations, ed. Henri Tajfel (London: Academic, 1978), 28-9; bdk. penjelasan dari Baker, "Social Identity Theory and Biblical Interpretation." 130; Esler, "An Outline of Social Identity Theory." 17.

${ }^{35}$ Baker, "Social Identity Theory and Biblical Interpretation." 130; Esler, "An Outline of Social Identity Theory." 17.

\footnotetext{
${ }^{36}$ Esler, "An Outline of Social Identity Theory." 17-8.
} 
Teks 1 Korintus 12 dimulai dengan penjelasan Paulus tentang kondisi jemaat di Korintus sebelum dan sesudah mereka mengenal Allah yang satu, yang mereka akui di dalam pengakuan iman Shema (1 Kor. 12:2-3). Transisi antara ayat 2 ke ayat 3 dalam 1 Korintus 12 dapat dipandang sebagai "ritual" keluarnya seseorang dari komunitas dan masuk dalam komunitas yang lain. ${ }^{37}$ Dalam teks 1 Korintus. 12, ritual yang menentukan batas komunitas berhubungan erat dengan gema Shema sebagai superordinate identity jemaat di Korintus. Seseorang yang masuk dan menghidupi identitas di dalam Shema tidak mungkin mengutuki Yesus karena keanggotaan tersebut mensyaratkan mereka untuk mengakui Yesus sebagai Tuhan (1Kor. 12:3). Menariknya, penjelasan Paulus tentang superordinate identity tersebut berada pada aspek kognitif. Berdasarkan versi teori Verbal Aspect yang digagas oleh Constantine Campbell, penggunaan tense-form perfect untuk kata kerja oidate dalam 1 Korintus 12:2 mengindikasikan adanya penekanan terhadap lexeme kata tersebut. ${ }^{38}$ Dengan demikian, jelas bahwa perhatian Paulus di sini ada pada aspek kognitif.

Transisi dalam 1 Korintus 12:2-3 juga memberikan keterangan bersifat evaluatif. Aspek evaluatif terlihat dari identifikasi terhadap hidup lama sebagai hidup yang belum mengenal Allah serta terikat pada berhala-berhala yang bisu, sedangkan dalam komunitas yang baru, mereka memiliki Allah yang menyatukan mereka. Selain itu, keberagaman di dalam ingroup identity juga dipandang sebagai sebuah nilai positif bagi komunitas (1Kor. 12:4-7, 11, 28-29). Dalam metafora tubuh, nilai positif dalam keberagaman juga sangat ditonjolkan, seperti dalam 1 Korintus 12:1718. ${ }^{17}$ Andaikata tubuh seluruhnya adalah mata, di manakah pendengaran? Andaikata seluruhnya adalah telinga, di manakah penciuman $?^{18}$ Tetapi, Allah telah memberikan kepada anggota, masing-masing secara khusus, suatu tempat pada tubuh, seperti yang dikehendaki-Nya. Kemampuan untuk melakukan evaluasi yang demikian tidak terpelas dari gema Shema yang hadir sebagai superordinate identity jemaat di Korintus.

Selain kedua aspek yang dijelaskan di atas, aspek emosional juga tampak dalam teks 1 Korintus 12. Dalam 1 Korintus 12:22 Paulus menjelaskan bahwa kekuatan yang dimiliki oleh jemaat harus digunakan untuk mendukung anggota yang memiliki kemelahan tertentu; perhatian semacam itu tidak dibutuhkan oleh anggota yang memiliki kecakapan tertentu atau dalam bahasa metafor tubuh, bagian yang elok (1Kor. 12:23-24). Ekspresi emosional seperti "jika satu anggota menderita, semua anggota turut menderita; jika satu anggota dihormati, semua anggota turut bersukacita" (1Kor. 12:26) menegaskan bahwa aspek emosional memainkan peran yang penting dalam identitas sosial jemaat di Korintus. Sekali lagi tujuan dorongan yang emosional tidak dapat dilepaskan dari gema Shema sebagai superordinate identity; karena tujuan dorongan tersebut adalah supaya tidak terjadi perpecahan di tengah jemaat (1Kor. 12:25).

\section{Konflik Jemaat dan Identitas Sosial Shema dalam 1 Korintus 12}

Gema terhadap Shema di 1 Korintus. 12 menegaskan kembali formasi identitas sosial jemaat di Korintus. Penekanan tersebut penting di tengah konflik yang dihadapi oleh jemaat di Korintus. 1 Korintus 12:1 memberikan indikasi bahwa fokus utama Paulus adalah tentang karunia-karunia Roh. Meskipun demikian, pembaca tidak boleh mengabaikan kenyataan bahwa masalah yang dihadapi oleh jemaat di Korintus cukup kompleks. Di 1 Korintus 3-4 Paulus memberikan respons terhadap masalah favoristisme di kalangan jemaat terhadap pemimpin rohani. Dalam 1 Korintus 8, 11, Paulus memberikan arahan tentang persoalan makan dan makanan yang memecah belah jemaat di Korintus. Meskipun kompleks, semua persoalan yang ada di Korintus mengarah pada

\footnotetext{
${ }^{37}$ Lamoreaux pernah menerapkan Teori Identitas Sosial dalam membaca masuknya Paulus menjadi komunitas "kekristenan awal," lihat: Jason T. Lamoreaux, "Social Identity, Boundary Breaking, and Ritual: Saul's Recruitment on the Road to Damascus," Biblical Theology Bulletin: Journal of Bible and Culture 38, no. 3 (August 2008): 122134.

${ }^{38}$ Constantine R. Campbell, Verbal Aspect, the Indicative Mood, and Narrative: Soundings in the Greek of the New Testament (New York: Peter Lang, 2007), 195-210.
} 
persoalan identitas. ${ }^{39}$ Kenyataan tersebut menjelaskan mengapa banyak ahli menaruh perhatian yang besar tentang isu identitas ketika membaca 1 Korintus. ${ }^{40}$

Seperti bagian lainnya, gema terhadap Shema dalam 1 Korintus 12 memberikan petunjuk tentang sikap Paulus terkait konflik yang dihadapi jemaat. Menurut Teori Identitas Sosial, konflik jemaat dalam 1 Korintus 12 dapat dijelaskan sebagai penekanan berlebihan dari anggota jemaat terhadap ingroup identity atau bahkan subordinate identity yang memiliki karunia-karunia yang terlihat spektakuler, seperti berbahasa roh. Sikap Paulus terhadap masalah tersebut adalah dengan menegaskan bahwa identitas jemaat tidak boleh didefinisikan pada level ingroup atau subordinate identity tetapi pada superordinate identity, yaitu relasi dengan Allah yang mereka imani dalam Shema. Dengan demikian, ingroup dan subordinate identity dapat dipandang sebagai sebuah kekayaan yang saling melengkapi superordinate identity.

Analisis dengan Teori Identitas Sosial juga memberikan informasi bahwa aspek kognitif, evaluatif, dan emosional yang dimiliki jemaat di Korintus tidak dapat dilepaskan dari gema Shema. Secara kognitif, masalah dalam jemaat tidak lagi diselesaikan seperti ketika mereka belum disatukan menjadi umat Allah. Mereka tidak lagi menyelesaikan konflik sebagai pengikut berhala-berhala bisu (bdk. 1Kor. 12:2). Mereka harus menyelesaikan masalah sebagai orangorang yang telah memiliki relasi dengan Allah (1Kor. 12:3). Secara evaluatif, jemaat di Korintus didorong untuk memandang nilai-nilai positif yang dimiliki oleh komunitas mereka. Dalam hal ini, keberagaman dipandang sebagai sebuah kekayaan untuk saling melengkapi tubuh Kristus yang satu (superordinate identity). Secara emosional, kesatuan sebagai bagian dari tubuh Kristus mendorong jemaat yang sedang berkonflik untuk saling memerhatikan, sehingga sukacita seorang anggota adalah milik bersama, demikian pula kesedihan seseorang adalah kedukaan semua anggota.

\section{KESIMPULAN}

Ketertarikan para sarjana terhadap 1 Korintus 12 sebagai teks yang dapat dibaca melalui kacamata penerimaan (inclusion) perlu diapresiasi. Artikel ini berupaya memberikan apresiasi serta kontribusi terhadap semangat tersebut melalui pembacaan Teori Identitas Sosial terhadap penggunaan bahasa keesaan (oneness language) di dalam 1 Korintus 12. Penulis berpendapat bahwa bahasa keesaan di 1 Korintus 12 merupakan gema dari pengakuan iman Israel yang paling terkenal, yaitu Shema. Shema yang digemakan tidak hanya menekankan dimensi teologis semata tetapi juga dimensi sosiologis. Penerapan Teori Identitas Sosial ke dalam pembacaan terhadap gema Shema tersebut memberikan jendela untuk memahami konfik dalam jemaat serta upaya penyelesaiannya.

Shema yang digemakan dalam 1 Korintus 12 merupakan superordinate identity yang mendefinisikan identitas jemaat di Korintus. Kesatuan jemaat harus didefinisikan dalam kerangka superordinate identity tersebut. Keberagaman dalam jemaat sebagaimana digambarkan dalam metafora tubuh dibaca sebagai ingroup atau subordinate identity, sehingga memperkaya komunitas bukan menjadi ancaman baginya. Gema terhadap Shema juga menjelaskan bagaimana ketiga aspek - kognitif, evaluatif, dan emosional - beroperasi dalam jemaat di Korintus. Setiap anggota jemaat didorong untuk fokus pada nilai-nilai positif serta kontribusi yang dapat mereka berikan bagi komunitas.

Kemunculan gema Shema dan pembacaanya dengan Teori Identitas Sosial memberikan kontribusi untuk memahami penyelesaikan konflik yang Paulus tekankan dalam 1 Korintus 12. Dalam menyikapi konflik, jemaat di Korintus harus merujuk kembali pada superordinate identity, bukan semata-mata pada ingroup dan subordinate identity mereka. Dengan demikian, kesatuan akan tetap dapat dipertahankan pada tingkatan yang esensial sambil mempertahankan kebera-

\footnotetext{
${ }^{39}$ Lihat J. Brian Tucker, "Baths, Baptism, and Patronage: The Continuing Role of Roman Social Identity in Corinth," in Reading Paul in Context: Explorations in Identity Formation (Essays in Honour of William S. Campbell), ed. J. Brian Tucker and Kathy Ehrensperger (London: Bloomsbury, 2013), 183-5.

40 Tucker, "Remain in Your Calling": Paul and the Continuation of Social Identities in 1 Corinthians, 61-79.
} 
gaman dalam komunitas. Jika superordinate identity menjadi fondasi, ketiga aspek sosial dari Teori Identitas Sosial memberikan strategi untuk merespons terhadap konflik yang sedang dihadapi. Strategi tersebut fokus pada keterlibatan jemaat dalam jemaat sebagai komunitas yang baru, bukan seperti ketika mereka ada dalam komunitas yang lama (penyembah berhala-berhala bisu).

\section{REFERENSI}

Baker, Coleman A. "Social Identity Theory and Biblical Interpretation." Biblical Theology Bulletin: Journal of Bible and Culture 42, no. 3 (August 2012): 129-138.

Bauckham, Richard. "Confessing the Cosmic Christ (1 Corinthians 8:6 and Colossians 1:1520)." In Monotheism and Christology in Greco-Roman Antiquity, edited by Matthew V. Novenson. Leiden: Brill, 2020.

Brock, Brian. "Theologizing Inclusion: 1 Corinthians 12 and the Politics of the Body of Christ." Journal of Religion, Disability and Health 15, no. 4 (October 2011): 351-376.

Byers, Andrew. "The One Body of the Shema in 1 Corinthians: An Ecclesiology of Christological Monotheism." New Testament Studies 62, no. 4 (October 2016): 517-532.

Campbell, Constantine R. Verbal Aspect, the Indicative Mood, and Narrative: Soundings in the Greek of the New Testament. New York: Peter Lang, 2007.

Carter, Timothy L. "Looking at the Metaphor of Christ's Body in 1 Corinthians 12." In Paul: Jew, Greek and Roman, edited by Stanley E. Porter. Leiden: Brill, 2008.

Esler, Philip F. "An Outline of Social Identity Theory." In T\&T Clark Handbook to Social Identity in the New Testament, edited by J. Brian Tucker and Coleman A. Baker. London: Bloomsbury, 2016.

Josephus, Flavius. The Works of Josephus: Complete and Unabridged, New Updated Edition. Edited by William Whiston. Peabody: Hendrickson, 1980.

Lamoreaux, Jason T. "Social Identity, Boundary Breaking, and Ritual: Saul's Recruitment on the Road to Damascus." Biblical Theology Bulletin: Journal of Bible and Culture 38, no. 3 (August 2008): 122-134.

Lim, Kar Yong. Metaphors and Social Identity Formation in Paul's Letters to the Corinthians. Eugene: Pickwick, 2017.

Reagan, Debra A. "Reclaiming the Body for Faith." Interpretation: A Journal of Bible and Theology 67, no. 1 (January 2013): 42-57.

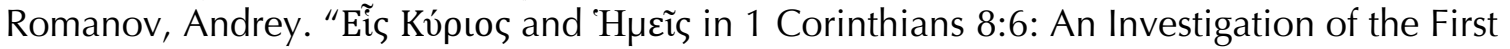
Person Plural in Light of the Lordship of Jesus Christ." Neotestamentica 49, no. 1 (2015): 47-74.

Saputra, Brury Eko. The Shema and John 10: The Importance of the Shema Framework in Understanding the Oneness Language in John 10. Eugene: Wipf and Stock, 2019.

Tajfel, Henri. "Interindividual Behavior and Intergroup Behavior." In Differentiation between Social Groups: Studies in the Social Psychology of Intergroup Relations, edited by Henri Tajfel. London: Academic, 1978.

Troupe, Carol. "One Body, Many Parts: A Reading of 1 Corinthians 12:12-27." Black Theology 6, no. 1 (September 2008): 32-45.

Tucker, J. Brian. 1 Corinthians: A Social Identity Commentary. London: Bloomsbury, 2021. . "Baths, Baptism, and Patronage: The Continuing Role of Roman Social Identity in Corinth." In Reading Paul in Context: Explorations in Identity Formation (Essays in Honour of William S. Campbell), edited by J. Brian Tucker and Kathy Ehrensperger. London: Bloomsbury, 2013.

_. "Remain in Your Calling": Paul and the Continuation of Social Identities in 1 Corinthians. Eugene: Pickwick, 2011.

- You Belong to Christ: Paul and the Formation of Social Identity in 1 Corinthians 1-4. Eugene: Pickwick, 2010.

Tucker, J. Brian, and Coleman A. Baker, eds. T\&T Clark Handbook to Social Identity in the New Testament. London: Bloomsbury, 2016. 
Tucker, J. Brian, and Aaron Kuecker, eds. T\&T Clark Social Identity Commentary on the New Testament. London: Bloomsbury, 2020.

Turner, John C. Rediscovering the Social Group: Self-Categorization Theory. New York: Blackwell, 1987.

Waaler, Erik. The Shema and The First Commandment in First Corinthians: An Intertextual Approach to Paul's Re-Reading of Deuteronomy. Tübingen: Mohr Siebeck, 2008.

Wright, N. T. The Climax of the Covenant: Christ and the Law in Pauline Theology. London: T\&T Clark, 1991.

Yong, Amos. The Bible, Disability, and the Church: A New Vision of the People of God. Grand Rapids: Eerdmans, 2011.

Yonge, C. D. The Works of Philo: Complete and Unabridged, New Updated Edition. Peabody: Hendrickson, 1993. 